\title{
El mito de pristinidad y los usos efectivos del territorio de la región de Magallanes, Patagonia Chilena: Forestal, minería y acuicultura
}

\section{The pristine myth and the direct land use pattern in the region of Magellan's, Chilean Patagonia: forestry, mining and aquaculture}

\author{
Luis Inostroza ${ }^{1}$
}

\section{INTRODUCCIÓN ${ }^{2}$}

En el estudio del medio el análisis de la naturaleza ha sido habitualmente concebido como algo frágil, amenazado por la actividad humana (Pillet, 2003). Esta fragilidad ha generado la creciente necesidad de estudiar acuciosamente los usos del territorio y de la naturaleza en él presente.

El uso del territorio responde a distintos objetivos socio-económicos: puede suministrar materiales y energía a través de la caza, la agricultura o la silvicultura, puede albergar infraestructura, o puede ser necesario para absorber residuos y emisiones (Haberl et al., 2004; Wrbka et al., 2004).

Los análisis de los cambios en los usos y cubiertas del suelo son cada vez más relevantes para determinar fricciones entre las sociedades y los ecosistemas que

\footnotetext{
${ }^{1}$ Institute of Photogrammetry and Remote Sensing, Technische Universität Dresden y Universidad Autónoma de Chile, Chile.

${ }^{2}$ El autor agradece el apoyo brindado por la Sra. Nelly Núñez de la CONAMA región de Magallanes, y Antártica Chilena por su apoyo en la búsqueda de información y al Sr. Nelson Moncada Jefe Depto. Administración y Fiscalización Forestal CONAF - Región de Magallanes y Antártica Chilena por la información sobre planes de manejo. Asimismo el autor agradece los comentarios de 3 revisores anónimos que permitieron mejorar la versión preliminar de este artículo.
} 
las soportan. Estos análisis son imprescindibles para la planificación territorial, la gestión hídrica, los procesos de erosión-desertificación, la pérdida de biodiversidad, entre otros (Murray et al., 2005). La gestión sostenible de la tierra, tratando de preservar la biodiversidad, requiere nuevas metodologías para la determinación de la capacidad general de usos del suelo y para su comparación con los usos actuales (Romero-Calcerrada et al., 2002). Sin embargo, la capacidad de los organismos de planificación y gestión territorial se ve obstaculizada por la escasez de información exhaustiva sobre los tipos y cambios en la cobertura y uso del suelo, y la evidencia aún menos sistemática sobre las causas, la distribución, las tasas y las consecuencias de esos cambios (Loveland et al., 2002).

El análisis de los usos y coberturas del suelo es un campo de gran interés para organizaciones de todo el mundo que han puesto en marcha numerosos proyectos para su cartografía y/o seguimiento. Existe una creciente necesidad de cartografiar la ocupación del suelo con amplio alcance espacial pero a una escala detallada, que sea susceptible de ser aplicada en el ámbito de la planificación territorial y el análisis medioambiental (Valera Lozano et al., 2012).

En la primera parte de este trabajo se hace una revisión de los actuales métodos de clasificación de los usos y sus limitaciones conceptuales y prácticas. En la parte metodológica se describe la forma en que fue desarrollado el modelo cartográfico de usos. Luego se presentan los principales resultados, destacando algunas actividades especificas como minería y usos forestales. Las implicaciones del trabajo son discutidas en las conclusiones.

\section{Problemas en los actuales sistemas de clasificación de usos y coberturas del suelo}

A pesar de la necesidad de un sistema estándar de clasificación de los usos del suelo, ninguna de las clasificaciones actuales ha sido aceptada internacionalmente (Fosberg, 1961; Eiten 1968, UNESCO, 1973, Mueller-Dombois \& Ellenberg, 1974; Kuechler \& Zonneveld, 1988; Europea C., 1993). Esto se debe a que en general las clasificaciones se han desarrollado para propósitos o escalas específicas y por lo tanto, no son adecuadas para otras iniciativas. Por otra parte, los criterios utilizados en los sistemas de clasificación mezclan de manera indeseable uso y cubierta del suelo, a veces incluyendo el clima como un parámetro (Di Gregorio \& Jansen, 2005). Un principio común subyacente que con frecuencia no se ha definido en la clasificación de la cubierta del suelo es la mezcla de diferentes características para definir una clase: clima, geología, tipo de suelo, forma de relieve, etc. Si bien estas características influencian las coberturas del suelo 
no son características inherentes de las mismas. Por ejemplo, en «selva tropical», el término «tropical», está relacionado con el clima, y sin embargo, se utiliza para describir una cierta composición florística. Este tipo de combinación es frecuente y se aplica de forma irregular, sin jerarquía, lo que da lugar a ambigüedades en la definición de las clases (Di Gregorio \& Jansen, 2005).

Muchos sistemas de clasificación existentes presentan una mixtura conceptual mezclando usos con coberturas del suelo. Estos dos términos siguen siendo utilizados indiferentemente, lo que es incorrecto pues representan aspectos diferentes de los componentes ambientales (Breuste et al., 2013; Meinel \& Hennersdorf, 2002). Así, áreas naturales o con vegetación casi natural se definen como cobertura del suelo, mientras agricultura y zonas urbanas por el contrario son usos del suelo. Se trata de dos aspectos diferentes. La distinción entre cubierta vegetal y uso del suelo es de importancia fundamental. Confundir estos dos términos y utilizarlos con ambigüedad conduce a problemas prácticos, sobre todo cuando los datos de ambas dimensiones deben ser armonizadas, comparados y/o combinados (Meinel \& Hennersdorf, 2002).

La cubierta del suelo es una descripción física del espacio, de la ocupación (bio) físicamente observada del suelo (Di Gregorio \& Jansen, 1997). Es una categorización física, química, ecológica o biológica de la superficie terrestre que da lugar a unidades superficiales específicas: bosque, pasto, cemento, asfalto, etc. (Murray et al., 2005) ${ }^{3}$. Indica lo que cubre la tierra y debe limitarse en un sentido puro y estricto a la descripción de la vegetación y las características artificiales. Se determina entre las siguientes categorías biofísicas clave: áreas de vegetación (árboles, arbustos, campos, prados), áreas no cultivadas (aunque esto significa que no hay cobertura), superficies duras (rocas, edificios) y humedales y cuerpos de agua (extensos cuerpos de agua, ríos, humedales). La cobertura del suelo es «observable» a diferentes distancias de la superficie de la Tierra: a simple vista, utilizando imágenes aéreas o de satélite a través de sensores remotos (Meinel \& Hennersdorf, 2002).

Por otra parte el uso del suelo corresponde a la dimensión funcional, es decir, a los propósitos socio-económicos del uso del territorio: usos residenciales, industriales o comerciales, agrícolas o forestales, áreas recreativas, áreas de conservación, etc. (Di Gregorio \& Jansen, 2005). Los usos del suelo se originan en las actividades que desarrollan las personas, actuando individual o colectivamente, con la intención de obtener productos o beneficios a partir de

3 http://www.ub.es/geocrit/b3w-571.htm - _edn7http://www.ub.es/geocrit/b3w-571.htm _edn7http://www.ub.es/geocrit/b3w-571.htm -_edn7. (Verificadas el 4/5/2015). 
los diferentes recursos (Murray et al., 2005) ${ }^{4}$. Sin embargo, usar significa hacer servir una cosa para algo (RAE, 2001: 2258), lo que implica que se trata de una acción o actividad humana directa, no potencial.

Se puede afirmar que la cubierta hace referencia al aspecto morfológico y tangible del suelo, mientras que los usos hacen referencia a las funciones que se desarrollan sobre aquellas cubiertas. En consecuencia una misma cubierta puede soportar diferentes usos: recolección, silvicultura y caza sobre cubiertas boscosas; y un mismo uso puede desarrollarse sobre diferentes cubiertas: turismo sobre cubiertas agrícolas o urbanas (Murray et al., 2005).

La definición del uso del suelo establece un cierto vínculo entre la cobertura del suelo y las acciones de las personas sobre él. Por ejemplo, "pastizales» es un término de la cubierta, mientras que el "pastoreo» se refiere al uso de esa cubierta de hierba; o "zona de recreo», que es un uso del suelo que puede ser aplicable a diferentes tipos de coberturas: superficies arenosas como playas, áreas construidas como parques de atracciones, bosques, etc. (Di Gregorio \& Jansen, 2005). A veces los aspectos funcionales pueden ser determinados por medio de los factores físicos (Duhamel \& Vidal 1998). Por analogía, el aspecto biofísico se puede derivar desde el aspecto funcional. Esta interrelación entre la cubierta y el uso, que en muchos aspectos es ambigua, en última instancia, significa que la cubierta y el uso requieren ser determinados por separado y no deben ser fusionados. Hay poderosos argumentos metodológicos y sectoriales en favor de una separación sistemática de usos y coberturas (Meinel \& Hennersdorf, 2002).

Por lo tanto, el uso del suelo sólo puede ser observado parcialmente y con frecuencia no directamente. Aun cuando es posible sacar conclusiones sobre los usos de las cubiertas vegetales y viceversa, la relación no es clara y evidente. En contraste con la cobertura del suelo, el uso es difícil de «observar». La información proporcionada por las fuentes de observación es habitualmente insuficiente y requiere información o detalles adicionales, como por ejemplo de los propietarios de tierras en el caso de la utilización agrícola (Meinel \& Hennersdorf, 2002).

Por otra parte una clasificación híbrida usos-coberturas también implica conceptualmente una concepción utilitarista del territorio, donde la sola cobertura indicaría el uso de dicha área. Por ejemplo, la categoría pastoreo (rangeland), actividad indicadora de un uso efectivo del territorio, es a veces interpretada como pastizales, volviendo a la definición de la cobertura y no del uso. Sin embargo,

\footnotetext{
4 http://www.ub.es/geocrit/b3w-571.htm - _edn6http://www.ub.es/geocrit/b3w-571.htm _edn6http://www.ub.es/geocrit/b3w-571.htm __edn6 (Verificadas el 4/5/2015).
} 
aquí se genera un vacío importante cuando se trata de determinar los usos (directos) en regiones remotas, donde aun persisten territorios sin uso.

Una parte de las clasificaciones actuales son o bien clasificaciones de vegetación (Por ejemplo, Danserau, 1961; Fosberg, 1961; Eiten, 1968; UNESCO, 1973; Mueller-Dombois \& Ellenberg, 1974; Anderson et al, 1976; Kuechler \& Zonneveld, 1988), amplias clasificaciones muy generales de la cubierta del suelo, o sistemas relacionados con la descripción de una función específica (por ejemplo, zonas agrícolas). Por lo tanto, están limitados en su capacidad de definir toda la gama de posibles clases de cubiertas del suelo. Un ejemplo es la clasificación de la vegetación UNESCO, que sólo tiene en cuenta la vegetación natural, mientras se ignoran todas las demás áreas con otra vegetación, como las zonas de cultivo y áreas con vegetación urbana. En contraste, los sistemas utilizados para describir las áreas agrícolas dan muy pocos detalles de la vegetación natural en su descripción (Di Gregorio \& Jansen, 2005).

Por otra parte en la mayoría de las clasificaciones actuales, los criterios utilizados para determinar clases no se aplican sistemáticamente. A menudo, la utilización de diferentes rangos de valores depende de la importancia dada por el usuario a una característica particular. Por ejemplo, en muchos sistemas las categorías se amplían para diferenciar zonas dominadas por árboles de diferentes especies, mientras que sólo se usa una sola gama para cubiertas de arbustos o zonas dominadas por hierbas. En algunas clasificaciones la definición de clase es imprecisa, ambigua o inexistente. Esto significa que estos sistemas no proporcionan consistencia interna (Di Gregorio \& Jansen, 2005).

Los valores de corte que se utilizan para diferenciar las distintas clases son muy a menudo derivados de conocimientos específicos de un área geográfica, de modo que en otros lugares la definición de esos límites de clase puede ser confusa, debido a solapamientos o lagunas. En estos casos cualquier comparación será imposible o imprecisa (Di Gregorio \& Jansen, 2005).

La teledetección ha jugado un rol fundamental en el desarrollo de los sistemas de clasificación de usos y coberturas. Las primeras aplicaciones de tecnologías de teledetección fueron en gran parte experimentales. Sin embargo, pronto se generó un campo en clasificación del uso y de la cubierta del suelo para determinar las condiciones de base para las áreas naturales y urbanas/suburbanas (Lunetta \& Elvidge, 1998). Estos esfuerzos fueron soportados por el sistema de clasificación jerárquico desarrollado por Anderson (Anderson et al., 1976), que estableció directrices para el mapeo de teledetección con una influencia que persiste hasta hoy (Rogan \& Chen, 2004, Franklin et al., 2003). Esta clasificación fue desarrollada para proveer de un sistema de clasificación de los usos y coberturas del suelo para el ordenamiento territorial y la gestión 
CuAdro 1

USOS Y COBERTURAS DEL SUELO USGS

\begin{tabular}{|c|c|c|}
\hline & NIVEL I & NIVEL II \\
\hline 1 & $\begin{array}{l}\text { Urbano, } \\
\text { Area edificada }\end{array}$ & $\begin{array}{l}\text { Residencial } \\
\text { Comercio y servicios } \\
\text { Industrial } \\
\text { Transporte, comunicaciones } \\
\text { Complejos industriales y comerciales } \\
\text { Mixto urbano o area edificada }\end{array}$ \\
\hline 2 & Tierras agricolas & $\begin{array}{l}\text { Cultivos y pastizales } \\
\text { Huertos, arboledas, viñedos, viveros y areas horticultura ornamental } \\
\text { Operaciones confinadas de alimentación } \\
\text { Otras tierras agricolas }\end{array}$ \\
\hline 3 & Pastoreo & $\begin{array}{l}\text { Pastizales herbáceos } \\
\text { Pastizales arbustivos y matorrales } \\
\text { Pastizales mixtos }\end{array}$ \\
\hline 4 & Bosques & $\begin{array}{l}\text { Bosque deciduo } \\
\text { Bosque siempreverde } \\
\text { Bosque mixto }\end{array}$ \\
\hline 5 & Agua & $\begin{array}{l}\text { Rios y canales } \\
\text { Lagos } \\
\text { Embalses } \\
\text { Bahías y estuarios }\end{array}$ \\
\hline 6 & Humedales & $\begin{array}{l}\text { Humedales boscosos } \\
\text { Otros humedales }\end{array}$ \\
\hline 7 & Suelos esteriles & $\begin{array}{l}\text { Planicies salinas } \\
\text { Playas } \\
\text { Otras áreas arenosas } \\
\text { Roca denudada expuesta } \\
\text { Minas, canteras y explotación de gravas } \\
\text { Áreas de transición } \\
\text { Suelos esteries mixtos }\end{array}$ \\
\hline 8 & Tundra & $\begin{array}{l}\text { Tundra arbustiva } \\
\text { Tundra herbácea } \\
\text { Suelo desnudo de tundra } \\
\text { Tundra húmeda } \\
\text { Tundra mixta }\end{array}$ \\
\hline 9 & $\begin{array}{l}\text { Hielos y nieves } \\
\text { eternas }\end{array}$ & $\begin{array}{l}\text { Nieves eternas } \\
\text { Glaciares }\end{array}$ \\
\hline
\end{tabular}

Fuente: derivada de Anderson et al., 1976.

Estudios Geográficos, Vol. LXXVI, 278, pp. 141-175, enero-junio 2015

ISSN: 0014-1496, eISSN: 1988-8546, doi: 10.3989/estgeogr.201505 
de actividades mediante teledetección, donde a través de la interpretación de distintas bandas espectrales es posible establecer las coberturas del suelo.

El sistema de clasificación de Anderson fue adoptado por la United Status Geological Survey (USGS), y es una de las clasificaciones más difundidas y utilizadas. Se divide en nueve categorías en tres niveles (ver cuadrol), de las cuales sólo tres representan usos del suelo. Las restantes seis categorías corresponden a coberturas del suelo.

\section{La categoría sin uso}

Los métodos utilizados para establecer usos en el caso de áreas urbanas, industriales o territorios intensamente utilizados - donde el ecúmene no tiene fronteras como Estados Unidos o Europa - han tenido una efectividad geográficamente limitada por singularidades locales. De esta forma tales clasificaciones resultan inconsistentes en contextos diferentes. En el caso particular de territorios despoblados o con amplias superficies no incorporadas al uso antrópico, como en la Patagonia, donde aun existen territorios sin utilizar, estas falencias se incrementan.

El aprovechamiento de los recursos naturales sólo es posible cuando éstos son accesibles y económicamente viables. Aquí hay restricciones espaciales y también técnicas. Espaciales por cuanto no se puede explotar aquellos territorios inaccesibles y tampoco aquellos que aun siéndolo no están al alcance de la tecnología disponible.

Resulta conceptualmente cuestionable otorgar categorías de uso a una naturaleza o territorio no intervenido antrópicamente, no transformado. El territorio estará en uso en la medida que hubiere sido incorporado a la esfera antrópica. Un bosque no puede considerarse «uso forestal» a priori, pues la sola presencia del atributo territorial no lo indica. Por lo tanto, categorías como bosque - cobertura - y forestal - uso - no son equivalentes. Tal aproximación no resulta válida en regiones con amplias superficies vírgenes, como la Patagonia. Se requiere determinar qué territorios tienen uso y cuales no mediante categorías adecuadas, incluyendo una categoría «sin uso».

\section{Área de estudio}

La región de Magallanes, corazón de la Patagonia Chilena, es un territorio político administrativo que se ubica en el extremo austral del continente americano, entre los paralelos $48^{\circ} \mathrm{S}$ y $60^{\circ} \mathrm{S}$ (figura 1 ). Limita al norte con los Cam- 
FIGURA 1

\section{UBICACIÓN GEOGRÁFICA CHILE Y REGION DE MAGALLANESX}

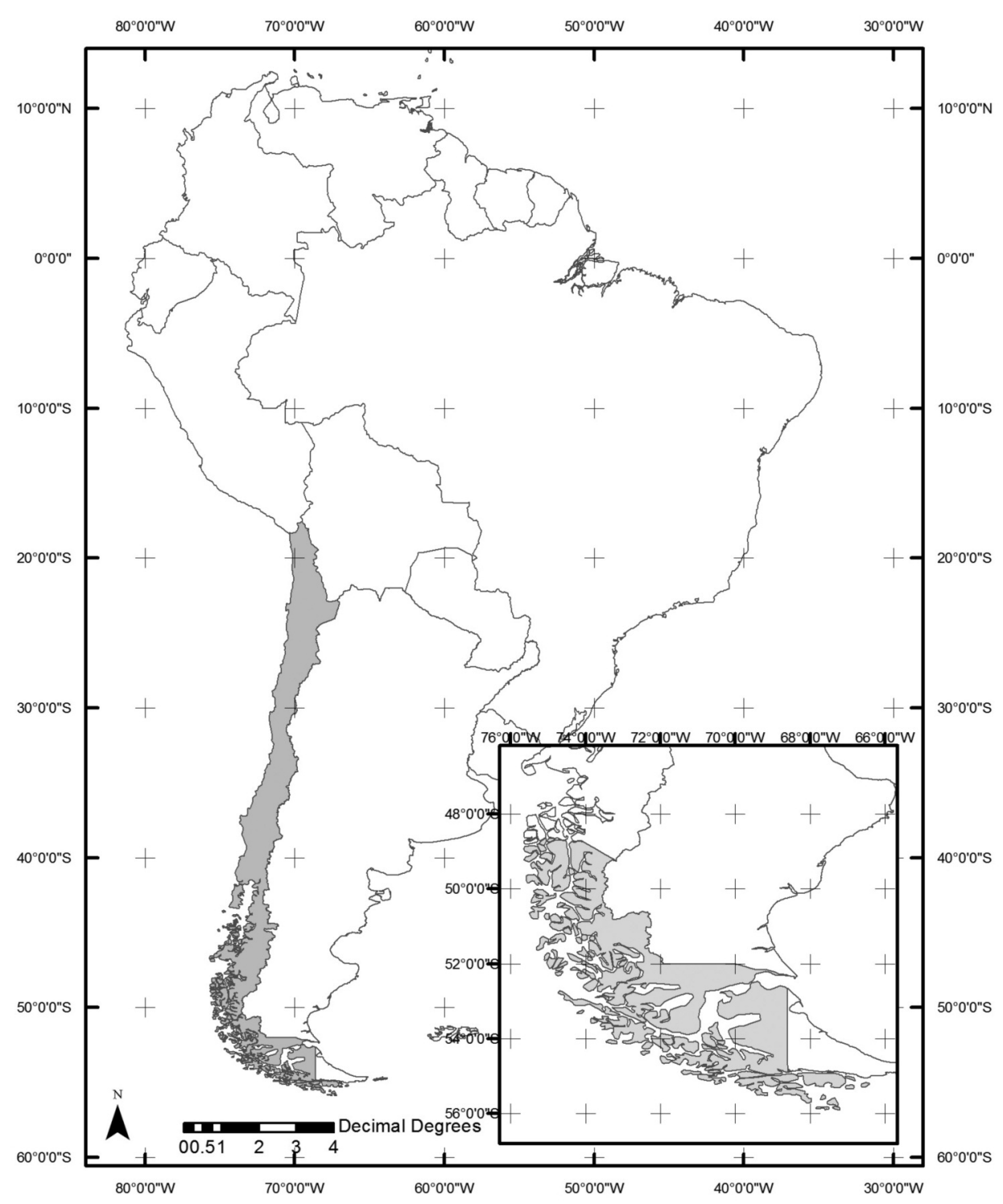

Fuente: elaboración propia.

Estudios Geográficos, Vol. LXXVI, 278, pp. 141-175, enero-junio 2015

ISSN: 0014-1496, eISSN: 1988-8546, doi: 10.3989/estgeogr.201505 
pos de Hielo Patagónico, y al oeste con la cordillera de los Andes, extendiéndose hasta el cabo de Hornos por el extremo sur. Con una población de sólo 150.000 habitantes y una superficie de $131.000 \mathrm{~km}^{2}$, que corresponde al 18\% de la superficie nacional, posee una de las densidades poblacionales más bajas del país. El 52\% del territorio esta incluido en el sistema nacional de áreas silvestres protegidas del estado (SNASPE).

\section{Usos del suelo en la región de Magallanes}

El principal diagnóstico de los usos territoriales es el catastro de usos del suelo y vegetación (Egaña \& Palma, 1999; CONAF-CONAMA, 2006). De las nueve categorías presentes en la clasificación sólo dos corresponden a usos del suelo (figura 2). Las siete categorías restantes corresponden a coberturas, donde el tipo de uso, o las áreas efectivamente utilizadas no tienen un reflejo adecuado. Según esta clasificación un $0.03 \%$ del territorio de Magallanes esta en uso urbano-agrícola-industrial, mientras que el $99.07 \%$ corresponde a coberturas de suelo naturales de las cuales se ignora su uso efectivo. Esta equivocada evaluación de los usos territoriales esta relacionada con las limitaciones metodológicas y epistemológicas anteriormente discutidas.

Así, la categoría bosques, cobertura bastante extendida en la región con una superficie total de $27.854 \mathrm{~km}^{2}$ no establece cuanto de esa superficie esta efectivamente explotada por actividades forestales.

Es necesario superar estas limitaciones en la evaluación de los usos del territorio y sus intensidades de explotación territorial. A fin de desarrollar una planificación territorial y ambiental más robusta se requieren metodologías que permitan cuantificar los usos del territorio, sus intensidades y patrones de distribución espacial.

El objetivo de este trabajo es cuantificar los usos efectivos del territorio de la región de Magallanes. Es una cuantificación que incluye las diferentes formas de explotación territorial permitiendo establecer cuanto territorio es efectivamente utilizado, qué actividades lo usan y cuanto remanente natural sin uso directo queda. En términos de objetivos específicos se trata de:

- Catastrar los usos del territorio y establecer la matriz de usos efectivos.

- Establecer el patrón espacial de los usos del territorio:

- Identificar y dimensionar la asignación de usos en el espacio.

- Cuantificar qué territorios involucran.

- Determinar los remanentes de territorio natural sin uso. 
FIGURA 2

USOS DEL TERRITORIO SEGÚN EL CATASTRO CONAMA

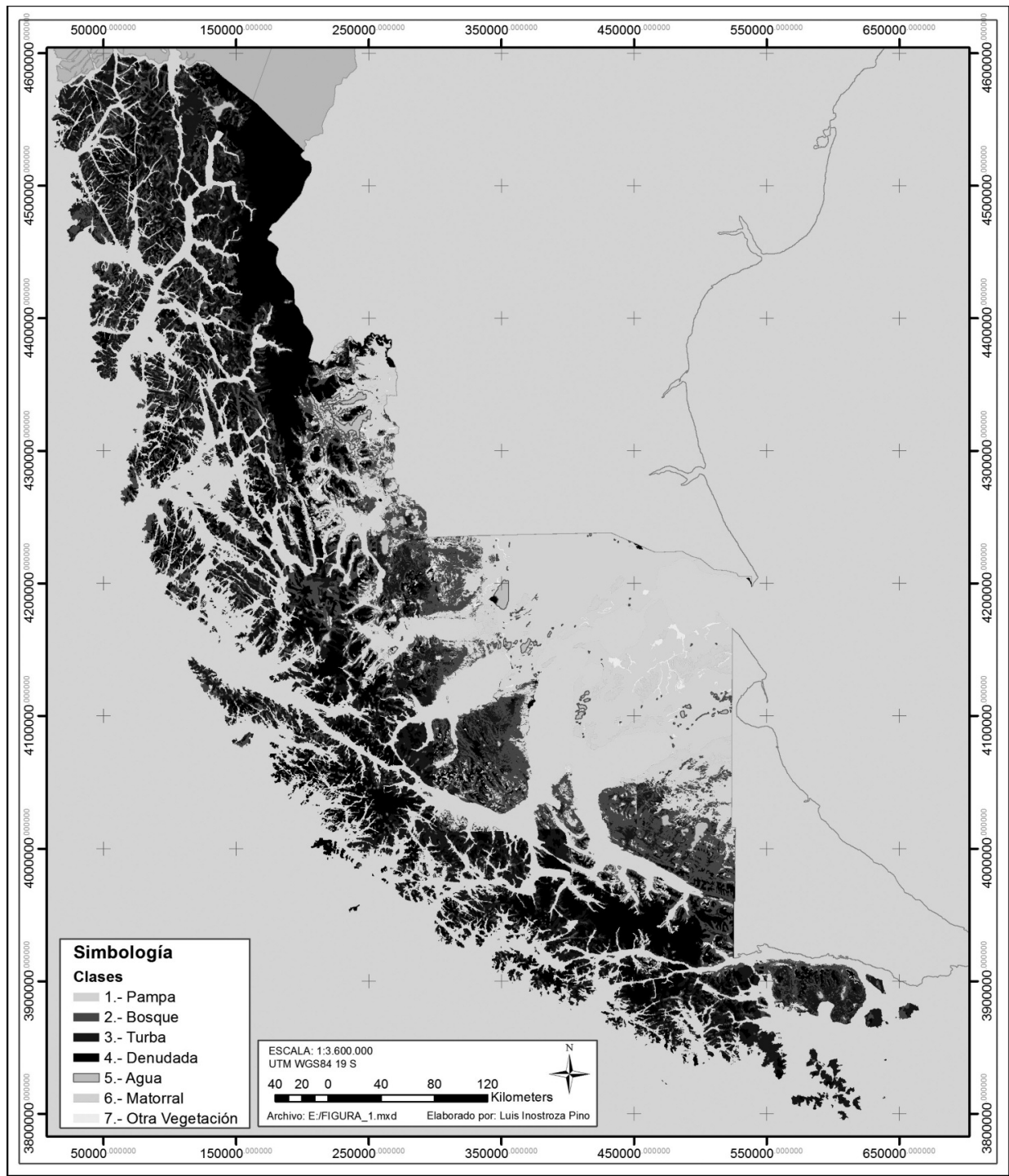

Fuente: elaboración propia.

Estudios Geográficos, Vol. LXXVI, 278, pp. 141-175, enero-junio 2015

ISSN: 0014-1496, eISSN: 1988-8546, doi: 10.3989/estgeogr.201505 


\section{MATERIAL Y MÉTODO}

Se han utilizado diversos materiales y fuentes de información geográfica para esta investigación. El método desarrollado se basa en un sistema de información geográfico (SIG). Mediante un modelo cartográfico se cuantifican los territorios en uso directo y sin utilizar. El modelo se desarrolló en tres fases sucesivas de reclasificación, depuración e integración y yuxtaposición. El mapa de usos del territorio refleja su uso efectivo y directo (figura 3).

Se toma como insumo base el catastro de usos del suelo y vegetación (España \& Palma, 1999). Esta cartografía fue elaborada en 1999 y actualizada en 2006 , sin embargo, presenta inconsistencias entre ambas versiones. Por otra parte también hay desajustes en las proyecciones y diversos errores menores y

\section{Figura 3}

MODELO CARTOGRÁFICO DE USOS DEL TERRITORIO

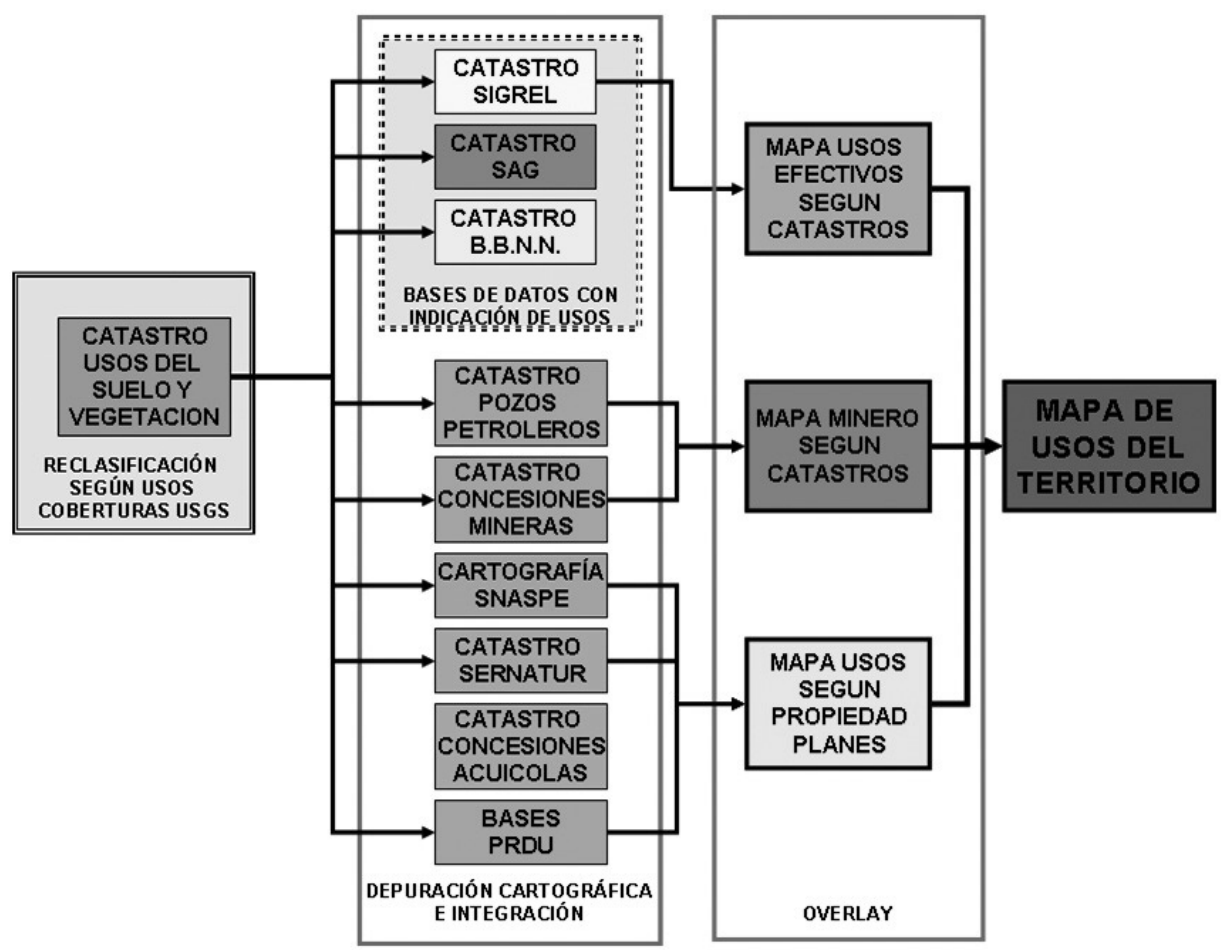

Fuente: elaboración propia. 
vacíos que han sido corregidos y complementados utilizando imágenes satelitales LANDSAT. Se han aplicado funciones estándar de los SIG para la depuración y la corrección de errores (Chrisman, 1989). Se reclasificaron las categorías según los usos y coberturas USGS (ver cuadro 1).

En una segunda fase se integran otras bases cartográficas con datos de propiedad. La depuración e integración de bases de datos da como resultado tres mapas preliminares: el mapa de usos según catastros, el mapa minero según catastros y el mapa de usos según propiedad o planes, que incluye acuicultura y turismo (figura 3). De la yuxtaposición resulta el mapa de usos del territorio, que refleja las áreas territoriales en uso efectivo y directo. No se incluye el SNASPE como uso, sólo las áreas específicas donde existen usos efectivos, a fin de evitar el sesgo de grandes superficies sin usos. La clasificación opera en dos niveles con 8 tipos y 16 usos (cuadro 2).

Cuadro 2

CATEGORÍAS PROPUESTAS DE USOS DEL TERRITORIO

\begin{tabular}{ccl}
\hline Tipo Nivel I & & Uso Nivel II \\
\hline \multirow{3}{*}{ Urbano } & 1 & Urbano \\
& 2 & Industrial \\
& 3 & Urbano turístico \\
& 4 & Agro residencial \\
\hline Ganadero & 5 & Ganadero \\
& 6 & Ganadero-forestal \\
& 7 & Ganadero-turístico \\
\hline Minería & 8 & Ganadero-petrolero \\
\hline Forestal & 9 & Minas explotación \\
\hline Acuicultura & 10 & Minas explotación \\
\hline Turístico & 11 & en Explotación \\
& 13 & Acuicultura \\
\hline Áreas Protegidas & 14 & Turismo escénico \\
\hline Natural & 15 & Áreas privadas \\
\hline
\end{tabular}

Fuente: elaboración propia.

Estudios Geográficos, Vol. LXXVI, 278, pp. 141-175, enero-junio 2015

ISSN: 0014-1496, eISSN: 1988-8546, doi: 10.3989/estgeogr.201505 
Los usos 1 al 15 corresponden a usos directos. La categoría urbano distingue entre urbano, industrial y agro-residencial, evidenciando las coronas residenciales adyacentes a las ciudades como nueva forma de utilización del territorio. El uso ganadero se divide en tres subcategorías: ganadero-forestal, ganadero-petrolero y ganadero-turístico, manifestando las mixturas de la base económica. El uso forestal, corresponde a explotaciones efectivas de bosques, según el catastro de planes de manejo de CONAF. La categoría minería corresponde a las concesiones mineras existentes poniendo a nivel de superficie la dimensión espacial de estas actividades y permitiendo su comparación. La categoría turismo se desagrega en ecoturismo y turismo escénico que reflejan dos formas de uso diferentes. La categoría áreas protegidas incluye únicamente aquellas de origen privado/concesionado: el parque marítimo Francisco Coloane y el Parque Karunkinca. Finalmente el octavo tipo corresponde a áreas naturales sin uso antrópico, que serian el saldo territorial como resultado del modelo, es decir aquellas áreas en las que no se identificó ningún uso directo y por lo tanto se consideran sin uso.

\section{Fuentes cartográficas utilizadas}

La región de Magallanes no posee cartografía oficial escala 1:50.000 para la totalidad de su territorio. Esto constituye un considerable retraso respecto del conocimiento de su territorio y de las posibilidades de desarrollo y sensibilidades que presenta. Por otra parte la cartografía disponible adolece de varias deficiencias que hicieron necesario un importante trabajo de integración cartográfica y actualización.

Una deficiencia importante en la cartografía existente es su alta atomización y la gran dispersión de sus formatos. A pesar de algunos esfuerzos como en Sistema Nacional de Información Territorial (SNIT), Magallanes no cuenta con cartografía normalizada. Cada institución decide las características técnicas de su cartografía de la manera que más le acomoda a sus objetivos institucionales. Esto produce «deseconomías» y duplicidad de esfuerzos.

Para conseguir un instrumento analítico consistente y técnicamente adecuado se ha hecho un esfuerzo considerable en la depuración de las bases cartográficas mediante el levantamiento de información, ajustes y correcciones de las fuentes de datos utilizadas. Toda la base cartográfica utilizada ha sido ajustada, complementada y depurada a fin de integrarla en un mosaico consistente. Se han hecho modificaciones en las proyecciones y datum, correcciones geométricas, complemento de superficies faltantes, calce general de entidades 
geométricas, complementos de base de datos y geocodificación de elementos geométricos. La base cartográfica integra las siguientes fuentes:

- CONAF-CONAMA, catastro de uso del suelo y vegetación, monitoreo y actualización. Región de Magallanes, 2006.

- SIGREL, SIG del Gobierno Regional de Magallanes y Antártica Chilena GORE.

- Cartografía Plan Regional de Desarrollo Urbano (PRDU), Ministerio de Vivienda.

- Cartografía y base de datos de predios del Servicio Agrícola y Ganadero (SAG).

- Cartografía y base de datos de predios del Ministerio de Bienes Nacionales (MBBNN).

- Catastro de Áreas Aptas para la Acuicultura, Oficina del Borde Costero, GORE Magallanes.

- Concesiones acuícolas otorgadas y vigentes 2007, CEQUA

- Ilustre Municipalidad de Punta Arenas, bases de datos y cartografía urbana.

- CONAF, archivo Excel con coordenadas de planes de manejo forestal 2000-2010.

- Cartografía áreas turísticas prioritarias, SERNATUR 2007. Esta planimetría en formato papel ha sido escaneada, georeferenciada y digitalizada a fin de integrarla con el resto de la base cartográfica.

\section{Incluyendo otros usos}

Existen importantes usos del territorio habitualmente no incluidos: minería, acuicultura y turismo. Para su incorporación en el modelo cartográfico se ha seguido un procedimiento específico en cada caso.

Para los usos mineros se utilizó la base de datos disponible en el sitio Web del Servicio Nacional de Geología y Minería (SERNAGEOMIN). Este sistema en línea es sólo de consulta y no permite el traspaso automático de la información. Se extrajo manualmente la información de las 644 concesiones mineras existentes en la región para construir un archivo SHP de puntos. El procedimiento fue el siguiente:

1. Se desplegó el mapa de concesiones mineras en la región de Magallanes (SAD-69/18 y SAD 69/19) en el software online.

2. Se traspasaron manualmente (punto a punto) los centroides de cada una de las concesiones visualizadas a un archivo SHP de puntos. 
3. Se transcribieron las coordenadas UTM de los centroides de las concesiones a un archivo DBF.

4. Se desplegó la base de datos de cada una de las concesiones -seleccionándolas en pantalla una por una- luego se traspasó manualmente dicha información a la base de datos del archivo SHP.

5. La información traspasada fue la siguiente:
a. Tipo de concesión: exploración o explotación.
b. El nombre del titular.
c. La situación: constituida o en trámite.
d. El año de inscripción (cuando estuvo disponible).
e. La superficie.

Las concesiones mineras se dividen según su tipo en exploración o explotación. Las solicitudes de exploración tienen una duración de dos años, pudiendo extenderse por otros dos años siempre y cuando se abandone la mitad del terreno solicitado originalmente.

La información cartográfica sobre hidrocarburos ha sido íntegramente desarrollada para efectos de este trabajo. Aun cuando la Empresa Nacional del Petróleo (ENAP) posee información digital de excelente calidad no fue posible obtenerla, por lo cual se utilizó la información análoga disponible: documentos publicados en Internet, memorias de gestión, planos, presentaciones públicas, etc. Esta se digitalizó y georeferenció, se geocodificaron las entidades geométricas y se poblaron las bases de datos.

Respecto de los usos turísticos del territorio existe un vacío, dado el amplio espectro de formas que puede asumir la actividad, desde el turismo urbano hasta el de naturaleza, con formas de uso distintas. Para determinar los usos turísticos se perfeccionaron las fichas de áreas turísticas 2010 (SERNATUR 2010) (atractivos repetidos, no localizados, etc.) y con otras fuentes locales y el conocimiento geográfico del autor. La ficha original no hace referencia a coordenadas lo que impide en algunos casos la localización del atractivo. Se eliminaron los atractivos ubicados dentro de ciudades, como museos, costaneras, etc., dado que por su escala no son posibles de utilizar en un estudio de corte regional. También se eliminaron las áreas SNASPE por tratarse de grandes extensiones territoriales; en su lugar se utilizaron los atractivos específicos localizados al interior de dichas áreas. El catastro turístico depurado contiene 153 atractivos localizados en un archivo SHP con su respectiva base de datos. 


\section{RESUlTAdos}

En su conjunto las actividades utilizan $65.270 \mathrm{Km}^{2}$, el $48 \%$ de la superficie regional. La ganadería es el uso predominante ocupando un 15\% de la superficie regional. El ecoturismo usa el 8,1\%, el turismo escénico el 5,5\%, los usos ganadero-petroleros el 5,4\% y la acuicultura el 5,3\% (figura 4). Al agrupar por tipos, la ganadería alcanza un 23,9\% del total regional $\left(32.469 \mathrm{~km}^{2}\right)$, el turismo un $15,8 \%\left(28.590 \mathrm{~km}^{2}\right)$ y la acuicultura un $5,3 \%\left(7.168 \mathrm{~km}^{2}\right)$, que representan en su conjunto un $45 \%$ del total regional $\left(61.067 \mathrm{~km}^{2}\right)$ (figura 6). Se trata de un territorio ganadero-turístico-acuícola.

Las áreas libres de usos antrópicos dejan un 52\% de remanente natural (figura 6), cifra que aunque coincide con la superficie del SNASPE tiene una

FIGURA 4

\section{PARTICIPACIÓN TOTAL DE USOS DEL TERRITORIO}

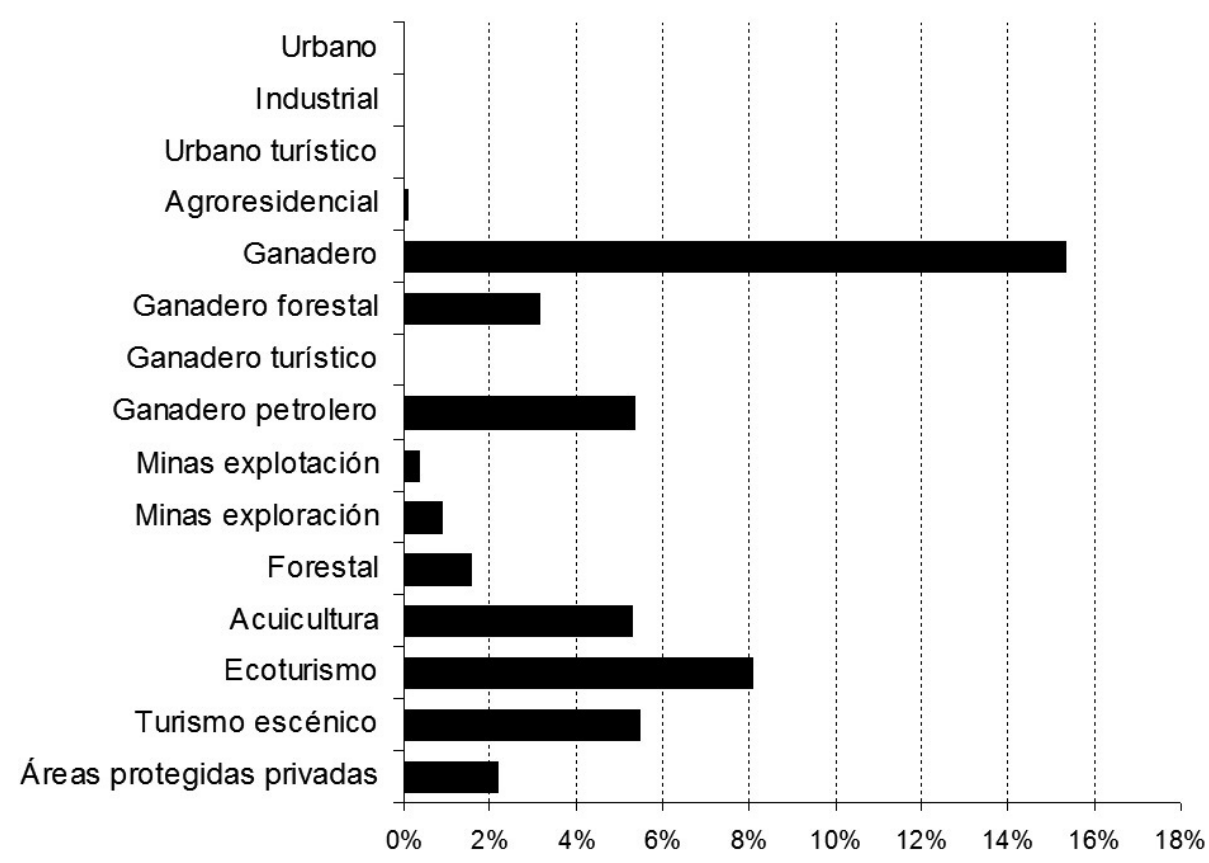

Fuente: elaboración propia. 
distribución espacial distinta. Dichos territorios, independiente de si pertenecen o no al SNASPE, no poseen usos efectivos posibles de constatar con el método empleado.

FIGURA 5

\section{USOS EFECTIVOS DEL TERRITORIO}

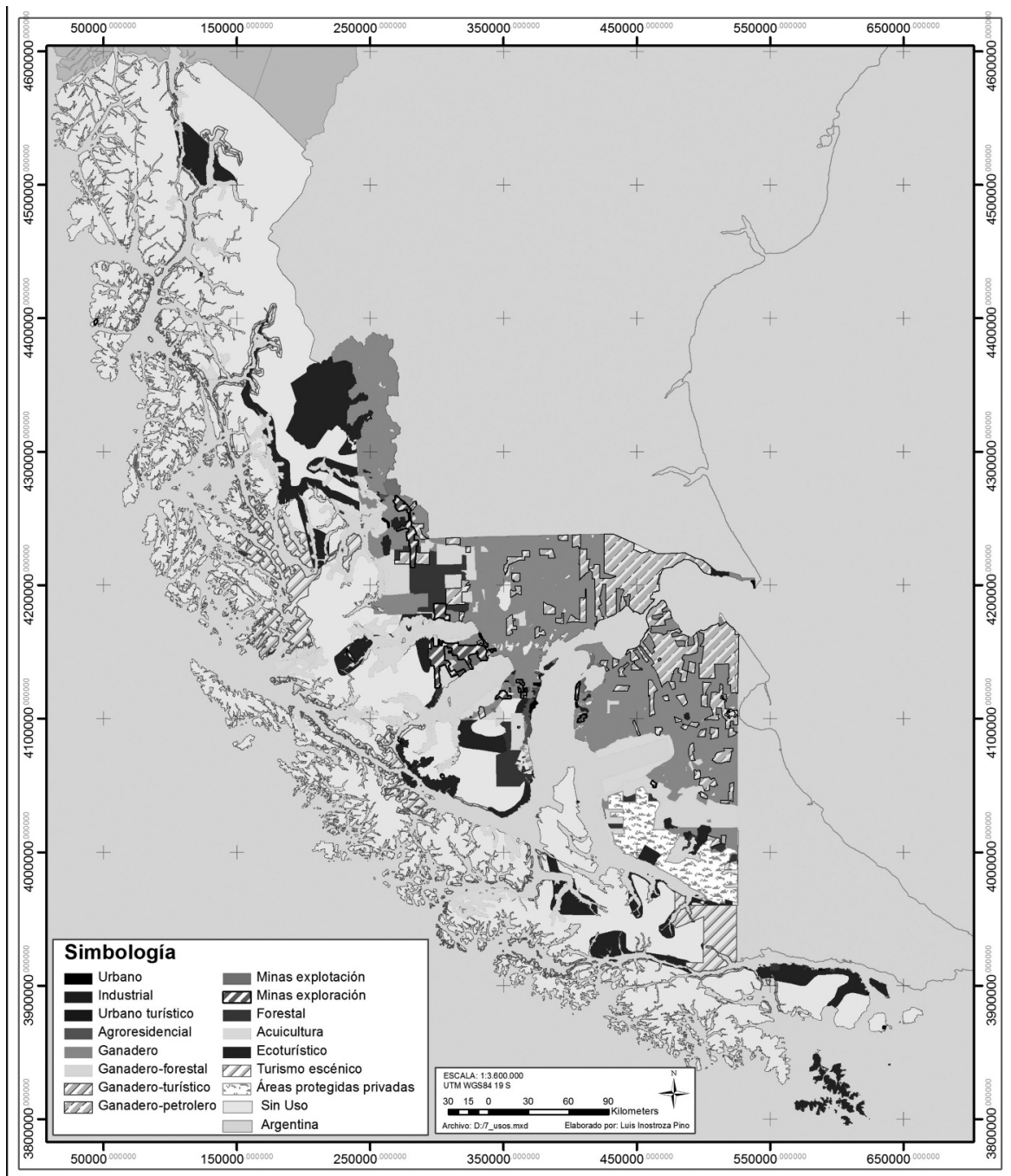

Fuente: elaboración propia. 
PARTICIPACIÓN DE PRINCIPALES USOS DEL TERRITORIO

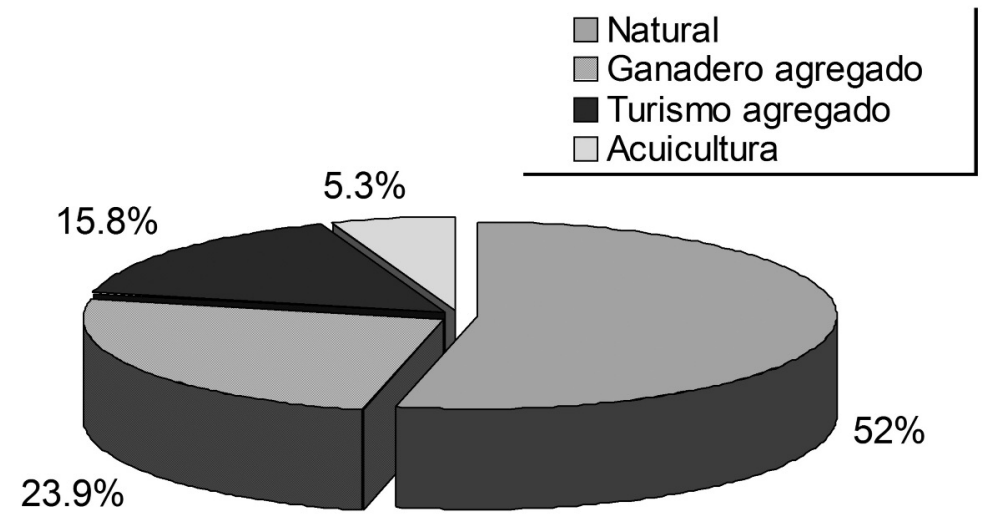

Fuente: elaboración propia.

\section{Uso forestal}

Durante la última década se han autorizado en promedio 3.000 ha anuales de explotaciones forestales (figura 8). Los planes de manejo autorizados se concentran en 4 sectores (cuadro 3, figura 7), asociados a la presencia de bosques de lenga: Rubens, Isla Riesco, Brunswyck y Tierra del Fuego Sur.

\section{CUADRO 3}

PLANES FORESTALES 2001-2010 POR SECTORES

\begin{tabular}{lccc}
\hline \multicolumn{1}{c}{ Sectores } & N $^{\text {o Planes }}$ & Há autorizadas & Total predial \\
\hline Sector Rubens & 135 & 13.584 & 1.129 .242 \\
Sector Isla Riesco & 10 & 895 & 63.292 \\
Sector Brunswyck & 64 & 6.054 & 340.877 \\
Sector Tierra del Fuego sur & 50 & 6.803 & 1.431 .756 \\
\hline
\end{tabular}

Fuente: elaboración propia. 
FIGURA 7

\section{SECTORES DE CONCENTRACIÓN PLANES FORESTALES}

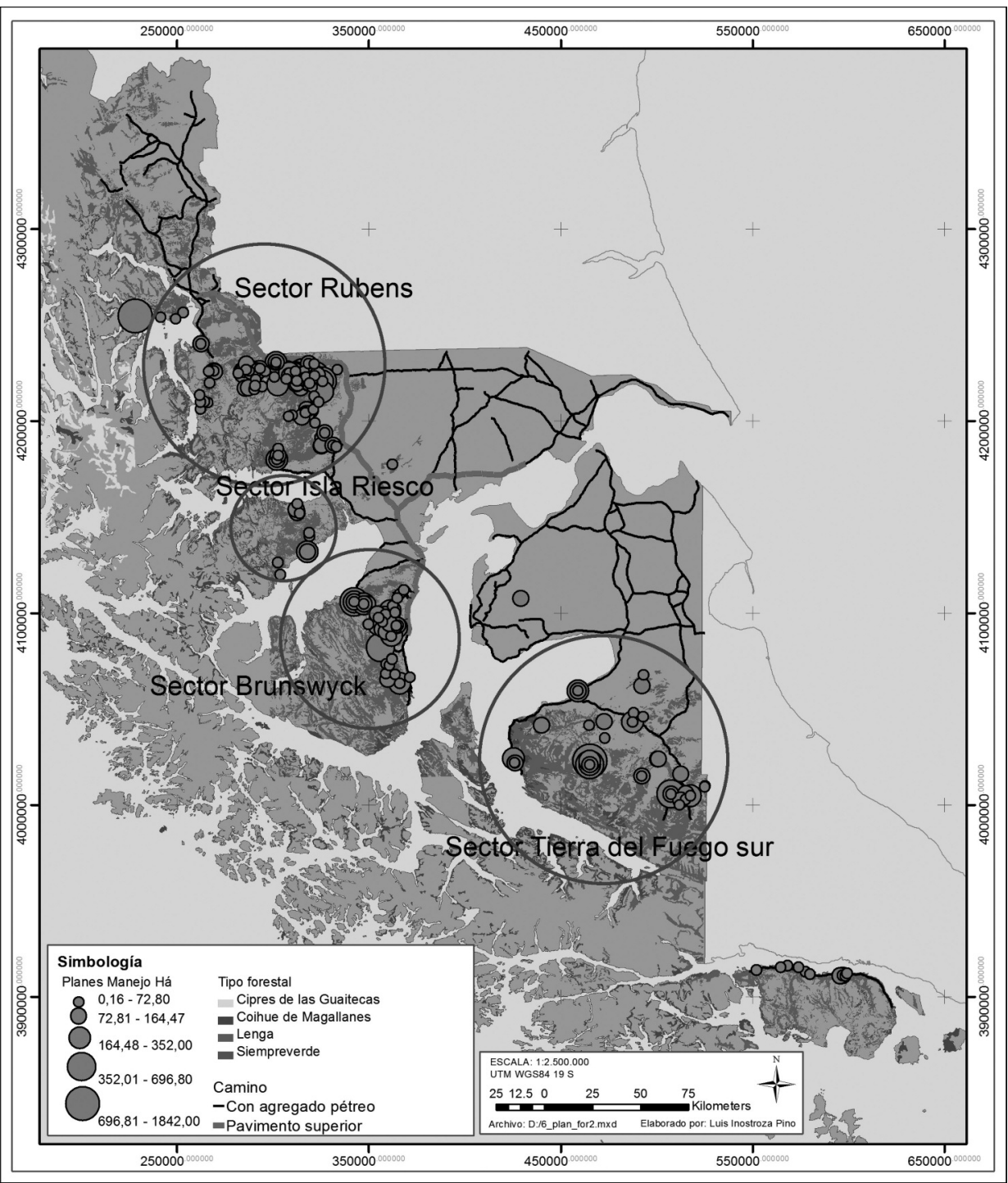

Fuente: elaboración propia. 
FIGURA 8

SUPERFICIE PLANES DE MANEJO AUTORIZADOS 2001-2010

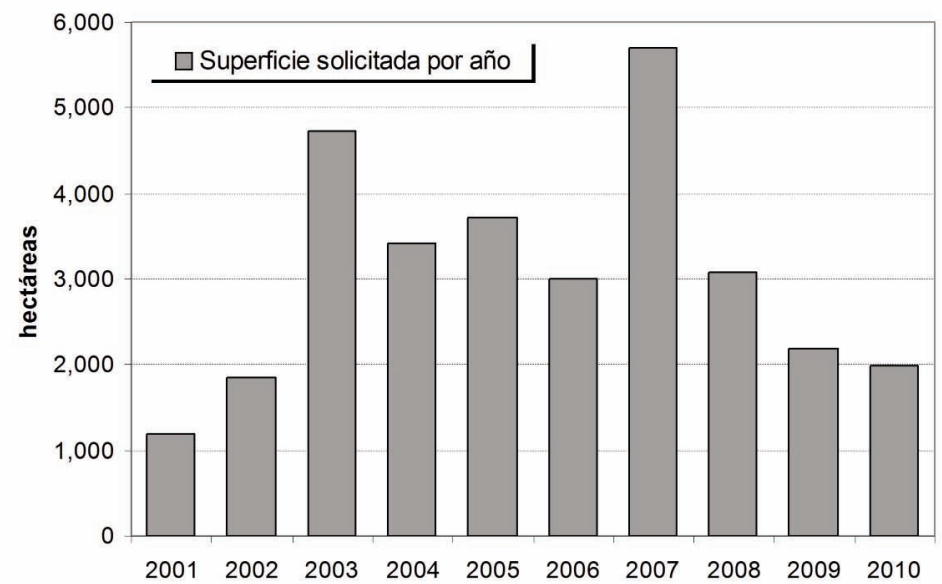

Fuente: elaboración propia, (datos CONAF).

\section{El territorio minero}

A marzo del 2010 la región de Magallanes registra 644 concesiones mineras. Un $44 \%$ están en trámite y un $56 \%$ están constituidas. En total ocupan el $1,4 \%$ de la superficie regional (cuadro 4 ).

CUADRO 4

CONCESIONES

\begin{tabular}{lclrc}
\hline \multicolumn{1}{c}{ Tipo } & \multicolumn{1}{c}{ Status } & $\mathrm{N}^{\mathbf{0}}$ & $\mathrm{Km}^{2}$ \\
\hline \multirow{2}{*}{ Concesiones de exploración } & \multirow{2}{*}{461} & Concesiones en trámite & 215 & 594 \\
& & Concesiones constituidas & 246 & 830 \\
Concesiones de explotación & \multirow{2}{*}{183} & Concesiones en trámite & 68 & 168 \\
& & Concesiones constituidas & 115 & 306 \\
\hline TOTAL & 644 & & 644 & 1.897 \\
\hline
\end{tabular}

Fuente: elaboración propia, (datos SERNAGEOMIN).

Estudios Geográficos, Vol. LXXVI, 278, pp. 141-175, enero-junio 2015

ISSN: 0014-1496, eISSN: 1988-8546, doi: 10.3989/estgeogr.201505 
Las concesiones de exploración ocupan el $75 \%$ de la superficie regional concesionada. Un $47 \%$ están en trámite y un 53\% constituidas. La región de Magallanes vive un auge minero. La importancia relativa de las concesiones de explotación es menor, sólo el $25 \%$ de la superficie total concesionada (cuadro 4).

Las concesiones mineras se distribuyen en 16 sectores (figura 9), concentrándose en cinco áreas: Natales, Skyring, Riesco, Brunswyck y Tierra del Fuego norte, con $90 \%$ del total de concesiones y de la superficie total concesionada. El sector de Riesco concentra la mayor actividad minera: el 45\% del total de concesiones vigentes y el $42 \%$ de la superficie concesionada. Todas corresponden a concesiones de carbón.

FIGURA 9

CONCESIONES POR SECTORES

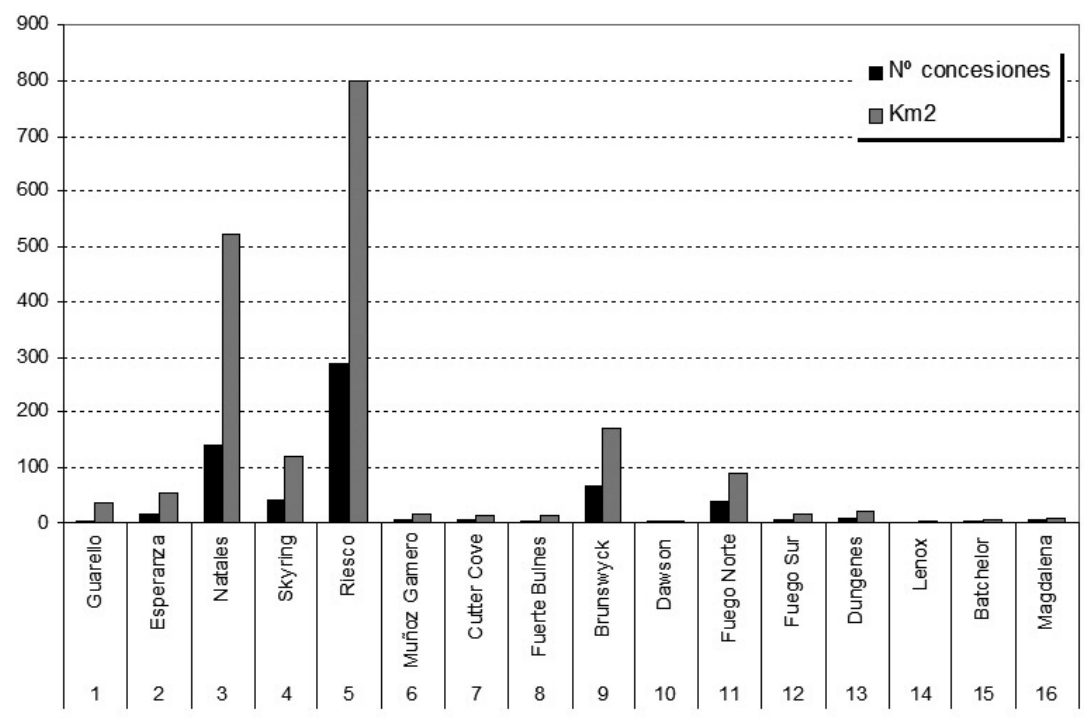

Fuente: elaboración propia, (datos SERNAGEOMIN).

Existe un claro predominio de las áreas en exploración, nuevos frentes de uso minero incorporados a la actividad: excepto en el caso de Tierra del Fuego Norte, más de 2/3 del total de concesiones en estos sectores son de exploración (cuadro 5, figura 10). 
CUADro 5

MAYORES SECTORES SEGÚN TIPO DE CONCESIÓN

\begin{tabular}{lrrrrr}
\hline \multicolumn{1}{c}{ Sectores } & Explotación & \multicolumn{1}{c}{$\%$} & Explotación & $\%$ & Total \\
\hline Natales & 32 & $22,7 \%$ & 109 & $77,3 \%$ & 141 \\
Skyring & 0 & $0 \%$ & 42 & $100 \%$ & 42 \\
Riesco & 64 & $22,1 \%$ & 225 & $77,9 \%$ & 289 \\
Brunswyck & 27 & $39,7 \%$ & 41 & 60,3 & 68 \\
Fuego Norte & 27 & $67,5 \%$ & 13 & 32,5 & 40 \\
\hline Total & 150 & $25,9 \%$ & 430 & 74,1 & 580 \\
\hline
\end{tabular}

Fuente: elaboración propia sobre datos SERNAGEOMIN.

Las cuatro áreas continentales corresponden a concesiones ubicadas en la cuenca carbonífera de Magallanes, la que posee cuatro sectores productores (CATAMUTUN):

Sector Brunswyck: el sector más prospectado ha sido Pecket, yacimiento actualmente en explotación. Posee más de 100 MMton de carbón, en dos mantos económicamente explotables. Las reservas económicamente recuperables con el sistema de rajo móvil, alcanzan aproximadamente a 50 MMton. Las reservas en otros sectores de la península de Brunswyck se han estimado en 1.200 MMton.

Sector Riesco: presenta las mayores reservas de Magallanes y del país, con varias zonas de interés e innumerables afloramientos conocidos. Las reservas se han estimado en 3.200 MMton. Es el sector que ha originado el auge de concesiones.

Sector Skyring: es un sector poco conocido y de menor importancia. Aquí opero la explotación de la mina Marta a fines del siglo XIX (Martinic, 2004). Se conocen algunos afloramientos frente al sector de ensenada de Posomby.

Sector Natales: se ubica entre el río Rubens y Puerto Natales. Estos carbones tienen mayor poder calorífico que los de zonas situadas más al sur. Las reservas de este sector se han estimado en 600 MMton.

El reciente auge minero en estos sectores responde al incremento del precio del carbón subbituminoso en los mercados internacionales y al aumento de la demanda país del sector energía eléctrica, el mayor consumidor (Gallegos \& Donoso, 1997). Toda esta explotación carbonífera se sustenta en de- 
FIGURA 10

CLUSTERING DE CONCESIONES: SECTORES Y TIPOS

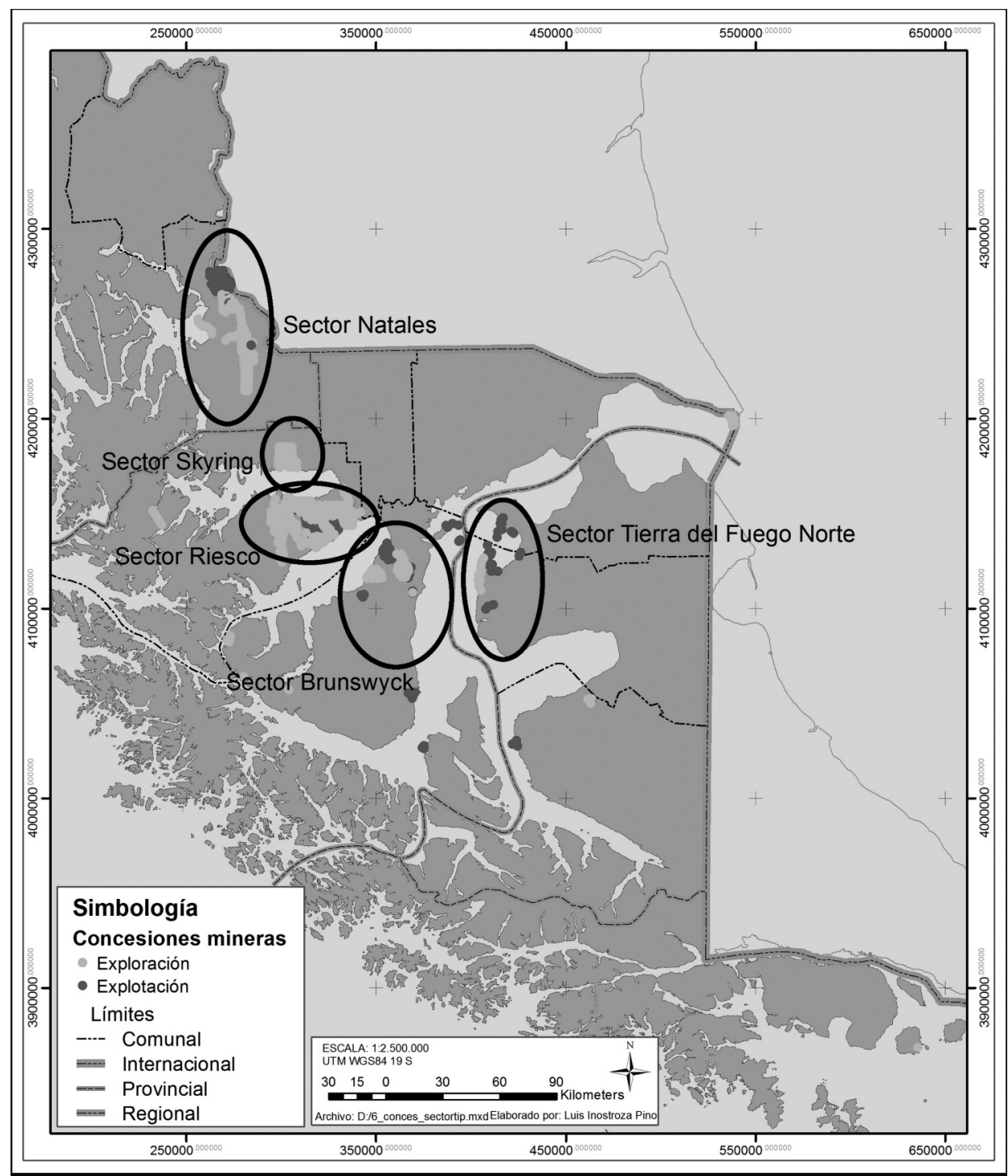

Fuente: elaboración propia. 
manda de mercados extra-regionales del sector de generación eléctrica. No existe demanda regional de carbón, las generadoras de electricidad de Magallanes funcionan a gas.

\section{Acuicultura}

El desarrollo de la acuicultura chilena se origina en la región de Los Lagos donde luego de consolidarse continua hacia el sur a la región de Aysén. Esta progresión espacial de la actividad también se manifiesta en los volúmenes de producción, donde para el año 2009 la región de Los Lagos participó con el 68,6\% de la producción acuícola nacional, la de Aysén con el 26,4\% y la de Magallanes con el 1,2\% (SERNAPESCA). El número de centros de acuicultura operativos inscritos en el registro nacional de acuicultura 2009 indica 2.179 (66\%) centros para la región de Los Lagos, 601 (18,2\%) centros en la región de Aysén y $64(1,94 \%)$ para Magallanes (SERNAPESCA). La región de Magallanes es el área geográfica ideal para la expansión de la actividad. La región presenta un crecimiento sostenido de la producción regional a pesar de su baja participación nacional (figura 11).

\section{FIGURA 11}

PRODUCCIÓN ACUÍCOLA TOTAL 1987-2009

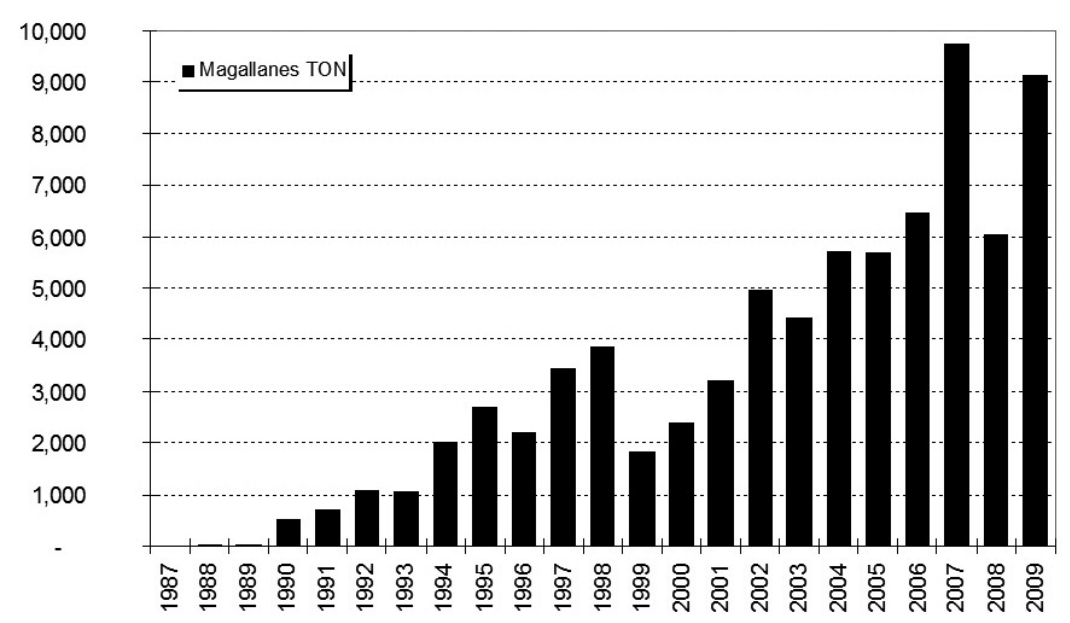

Fuente: elaboración propia, (datos Sernapesca). 
FIGURA 12

ÁREAS APTAS PARA LA ACUICULTURA VIGENTES

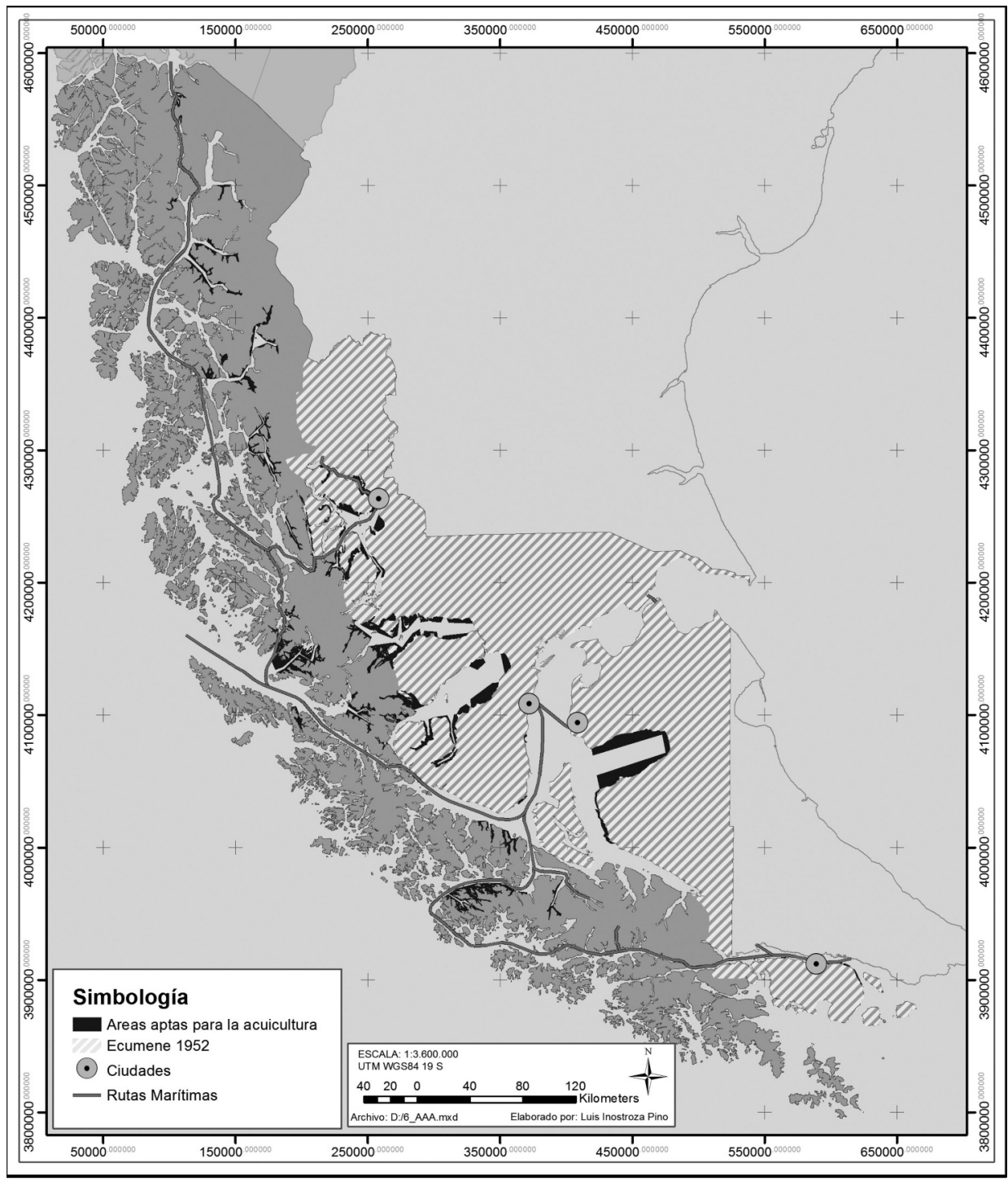

Fuente: elaboración propia. 
Para su desarrollo la acuicultura requiere atributos geográficos específicos: geomorfología del territorio, presencia de aguas protegidas (aguas interiores, canales, fiordos) y limpias. Estas especiales aptitudes territoriales fueron oficialmente reconocidas en el año 1994 en el decreto que establece las áreas aptas para la acuicultura (AAA) en la región (figura 12). Originalmente se establecía gran parte de las aguas interiores como aptas para la acuicultura, lo que ha sido motivo de numerosas modificaciones, eliminando áreas declaradas, reduciendo superficies y precisando localizaciones. A la fecha las áreas declaradas aptas para la acuicultura suman 442.050 ha, sólo considerando el cuerpo de agua sin incluir las áreas de respaldo terrestre, superficie similar al área potencial de explotación forestal.

A esto se suman los problemas ambientales de la industria en las regiones de Los Lagos y Aysén, que han producido un efecto regional, incrementando exponencialmente las demandas acuícolas por uso del territorio (figura 13). Producto de la crisis en las regiones acuícolas la tendencia incremental en las solicitudes se ha mantenido. Se trata de solicitudes de salmonicultura, las que sumaron 979 para el año 2009 contra 53 vigentes (SUBPESCA).

FIGURA 13

SOLICITUDES DE CONCESIÓN ACUÍCOLA Y PRODUCCIÓN

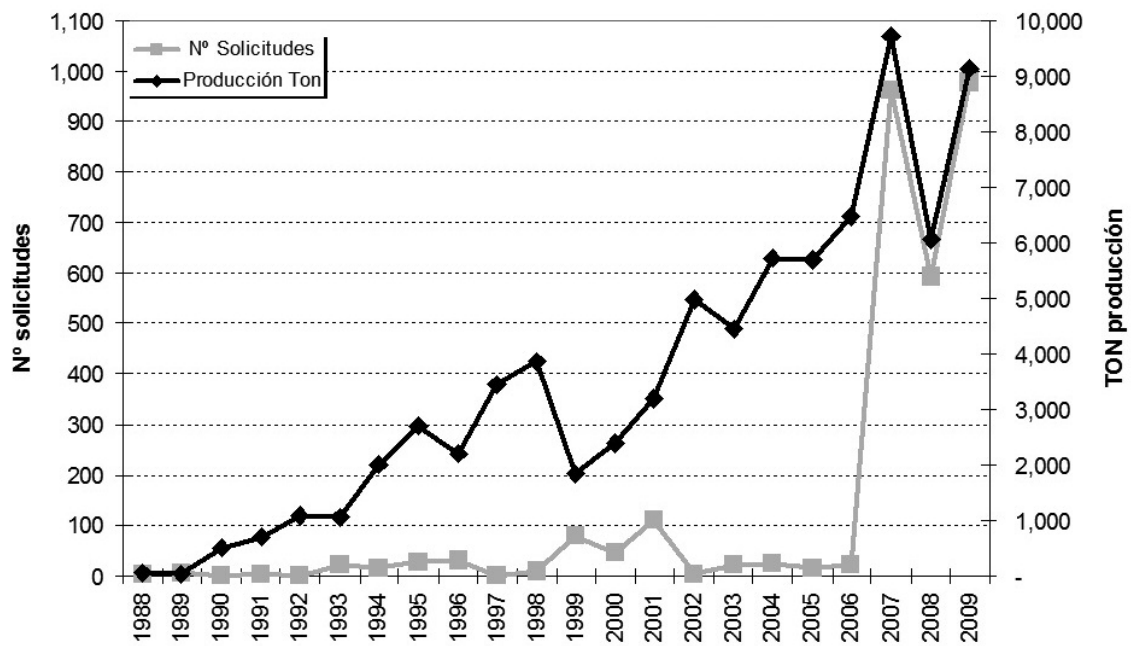

Fuente: elaboración propia, (datos SERNAPESCA). 
FIGURA 14

PROPUESTA GORE DE CAMBIOS EN ÁREAS APTAS PARA LA ACUICULTURA

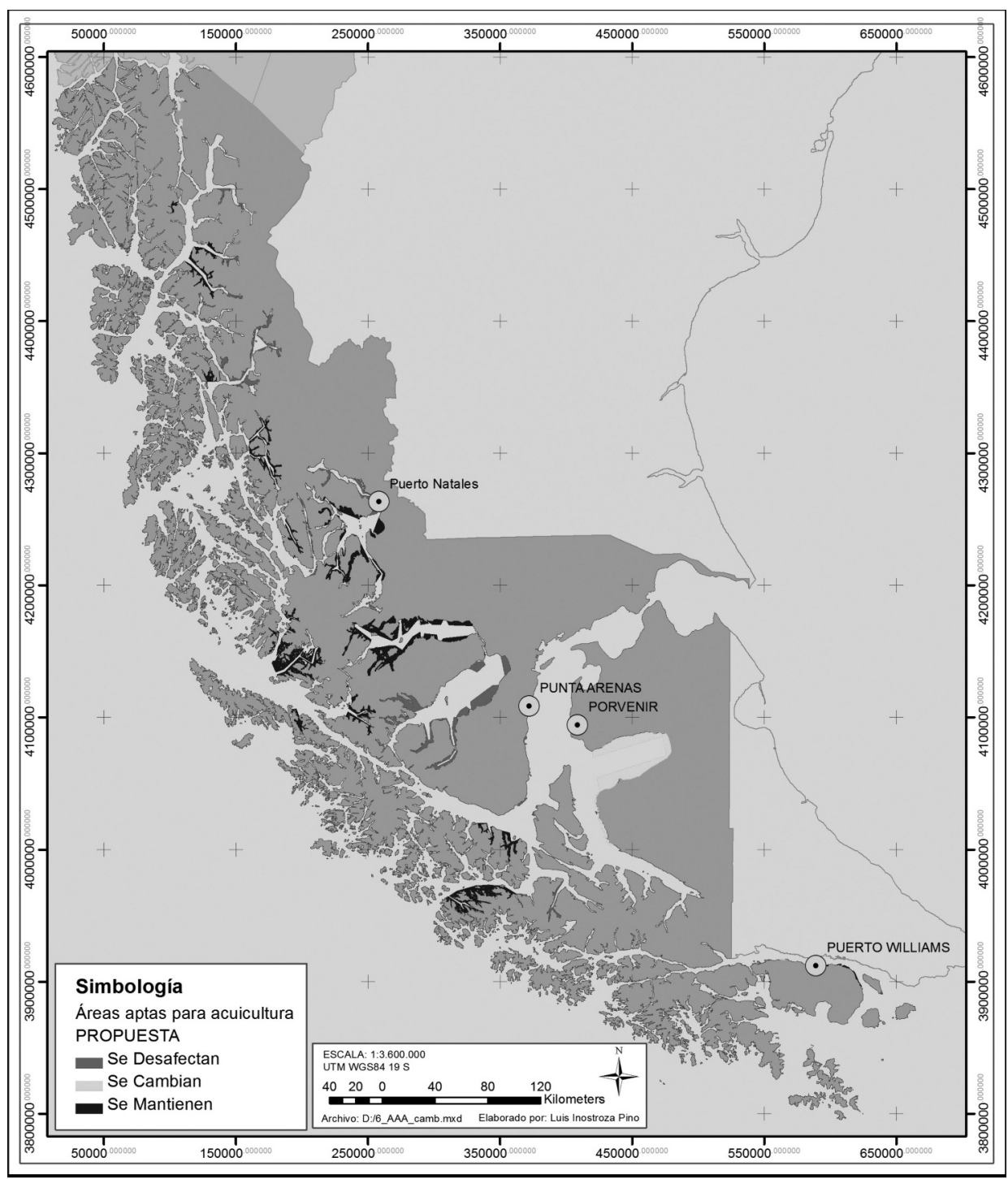

Fuente: elaboración propia. 
FIGURA 15

\section{SOLICITUDES DE CONCESIÓN SALMONICULTURA 2009 Y ÁREAS DE CONFLICTO}

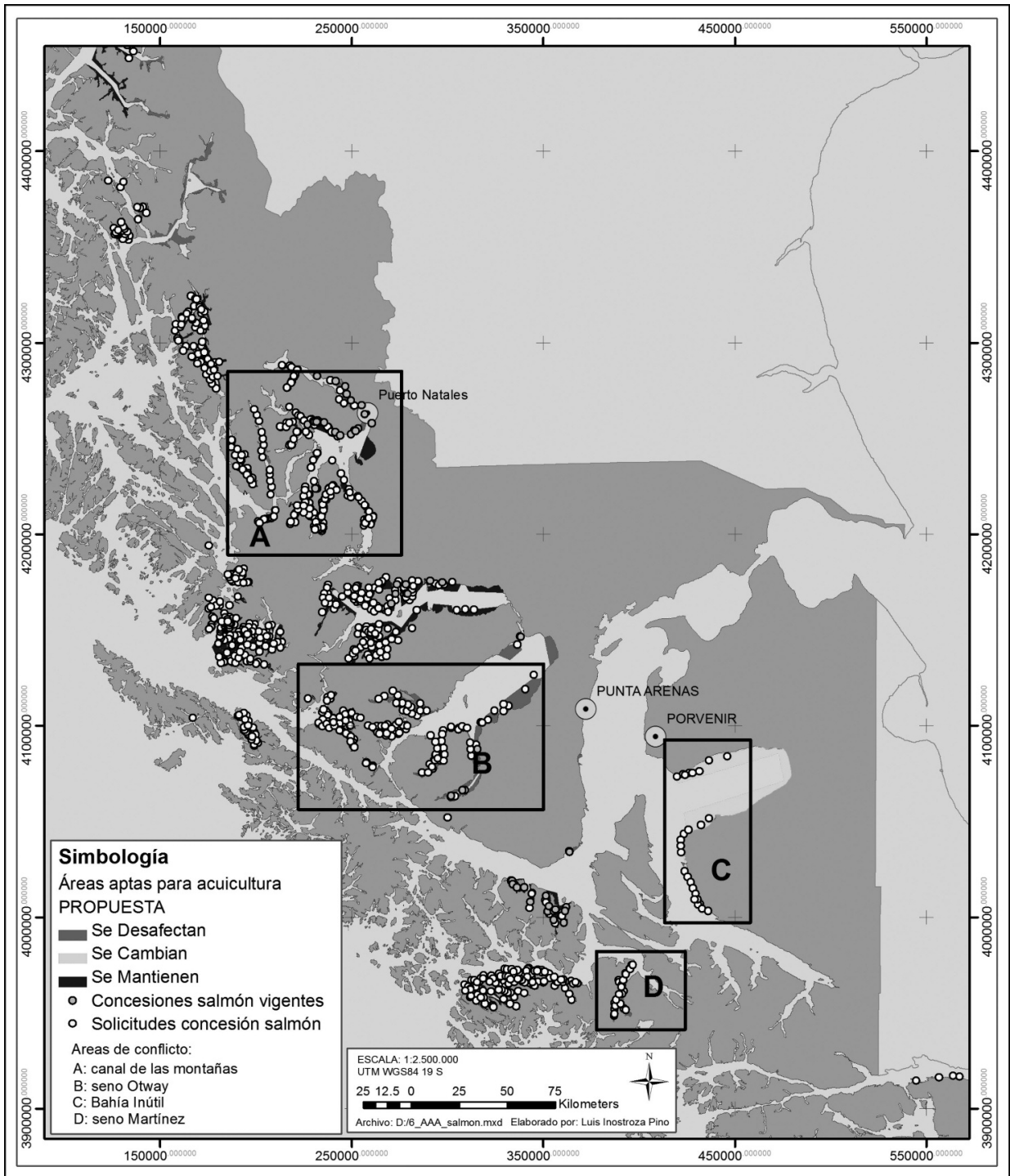

Fuente: elaboración propia.

Estudios Geográficos, Vol. LXXVI, 278, pp. 141-175, enero-junio 2015

ISSN: 0014-1496, eISSN: 1988-8546, doi: 10.3989/estgeogr.201505 
La habilitación de áreas para el desarrollo de la acuicultura ha sido motivo de insistente cuestionamiento por parte del sector turismo y pesca artesanal, que ven amenazados sus intereses con la creciente presencia de la actividad en la región. En este contexto el Gobierno Regional de Magallanes (GORE) ha elaborado una propuesta de modificación (figura 14) incluida en el estudio de zonificación del borde costero en desarrollo, que propone mantener el 53\% de las AAA existentes, cambiar de posición el $21 \%$ y eliminar el 23\% restante. De existir acuerdo sobre tales proposiciones todavía se requiere un largo proceso de participación ciudadana y aprobación para que tales cambios entren en vigencia. Mientras la industria acuícola ya ha tomado posiciones en las áreas actualmente autorizadas mediante un centenar de nuevas solicitudes, que generan conflicto con la propuesta de cambio en al menos 4 sectores (figura 15). Durante el 2007 el sector del canal de las montañas recibió 63 nuevas solicitudes, Seno Otway 39, Bahía Inútil 29 y Seno Martínez 29, que se suman a las concesiones acuícolas vigentes en dichos sectores. En la práctica los derechos adquiridos por dichas solicitudes y concesiones impiden que sean caducadas lo que hace inviable la propuesta de cambio en dichas áreas de conflicto.

\section{CONCLUSIONES}

Los actuales sistemas de clasificación de los usos del suelo han demostrado importantes falencias en su aplicación a contextos geográficos específicos. Esto indica que además de flexibles y conceptualmente claros los sistemas de clasificación localmente concebidos reflejan de mejor manera los usos de territorios específicos.

En Chile se han desarrollado varios intentos de mapeo de los usos/coberturas, de los cuales uno de los más importantes ha sido el catastro de usos del suelo y vegetación (Egaña \& Palma, 1999; CONAF-CONAMA, 2006), el que ha planteado un sistema de clasificación homogéneo para todo el país. Si bien es cierto se entienden las necesidades de comparación a nivel nacional, el plantear un sistema homogéneo y rígido para un país geográficamente tan diverso como Chile presenta grandes riesgos. Es necesario avanzar en sistemas flexibles y jerárquicos que permitan diagnósticos más realistas de las realidades regionales.

El método de clasificación propuesto refleja el alcance de los usos del territorio en la región de Magallanes de manera directa y efectiva. Constituye un elemento de análisis más robusto en términos de usos que las mediciones del catastro de usos del suelo y vegetación que subestima las actividades puntuales y no incluye usos importantes como minería, acuicultura y turismo. 
En algunos casos como en la minería y forestal se trata de explotaciones localizadas en sectores de importancia ecológica en la transición ecosistémica estepa-bosque andino patagónico, en corredores ecológicos transversales en un territorio altamente fragmentado (Inostroza, 2008). También hay un desplazamiento importante del umbral histórico de la actividad minera hacia el Pacífico y cuyo alcance espacial es muy superior al umbral potencial de explotación de hidrocarburos. Se trata de actividades de tipo extractivo-intensivo, sin valor agregado y supeditadas a un sistema de precios internacionales que deja poco margen para manejos que consideren el medio ambiente.

Por su parte la acuicultura presenta incompatibilidades con actividades como el turismo por el impacto de las instalaciones en el paisaje, además de otros efectos significativos que la actividad produce sobre los ecosistemas marinos (FAO, 2009). Sin embargo, más allá de esta competencia económica por el uso del territorio, existen otros efectos, como la introducción de patrones de uso del territorio, apertura de accesibilidades, áreas de respaldo terrestre, sistemas de transporte, instalaciones etc., que colonizan nuevos territorios abriéndolos a su utilización económica y de esta manera las puertas para el ingreso de otras actividades y economías de escala antes inexistentes.

Respecto del turismo el resultado indica que el rol del SNASPE aún permanece latente, con utilizaciones incipientes y un turismo todavía en fases de expansión incorporando nuevos territorios.

La Patagonia chilena, producto de las formas y patrones de explotación del territorio, utiliza el $48 \%$ de su superficie de manera directa a pesar de parecer un territorio virgen. Esta ecuación de utilización extensiva-intensiva-imperceptible en un territorio ecológicamente frágil pone en riesgo los delicados equilibrios existentes. Algunos ecosistemas como el de estepas ya están en avanzados procesos de utilización e incluso deterioro (Inostroza, 2012). Desde la perspectiva del uso, la virginidad del medio natural de la región de Magallanes pierde consistencia, es el mito de la pristinidad, el que se ha configurado de manera similar a lo que describe Denevan para las Américas precolombinas (Denevan, 1992), en una situación mítica basada en percepciones carentes de sustento científico, y donde él se avoca a demostrar la intensidad en la utilización y explotación del continente americano previo a la llegada de Colon. De manera similar en la Patagonia Chilena y debido al uso extensivo y a los desequilibrios ambientales provocados por los nuevos e incontrolados usos, se trata de un territorio extensivamente utilizado y no inmaculado. Es la paradoja del medio natural: la Patagonia chilena está siendo utilizada extensivamente a pesar de parecer un territorio virgen y de ser tratada por sus habitantes y autoridades como tal. 
Fecha de recepción: 18 de junio de 2013.

Fecha de aceptación: 3 de octubre de 2013.

\section{BiBLIOGRAFÍA}

Anderson, B. J. R. (1976): A Land Use And Land Cover Classification System For Use With Remote Sensor Data. Washington D.C., US Government Printing Office.

Breuste, J., Haase, D. \& Elmqvist, T. (2013): "Urban Landscapes and Ecosystem Services", in S. Wratten, H. Sandhu, R. Cullen, \& R. Constanza (eds.): Ecosystem Services in Agricultural and Urban Landscapes. Chicester,Wiley \& Blackwell, pp. 83-104.

Chrisman, N. R. (1991): "The error component in spatial data". Geographical information systems, 1/12: pp. 165-174.

Chrisman, N. R. (1989): "Modelling error in overlaid categorical maps", in M. F. Goodchild y S. Gopal (eds): Accuracy of spatial databases. London, Taylor \& Francis, pp. 21-34.

CONAF-CONAMA. (2006). Catastro de uso del suelo y vegetación, región de Magallanes y Antártica Chilena. Monitoreo y actualización. Santiago de Chile, p. 14.

Denevan, W. M. (1992): "The Pristine Myth: The Landscape of the Americas in 1492". Annals of the Association of American Geographers, 82/3, pp. 369-385.

Di Gregorio, A., \& Jansen, L. J. M. (1997): "A new concept for a land cover classification system". Proceedings of the Earth Observation and Environmental Information 1997, Alejandría, Egipto, Conference, pp. 13-16.

Di Gregorio, A. (2005). Land cover classification system: classification concepts and user manual: LCCS (No. 8). Roma, Food \& Agriculture Org.

Duhamel, C. \& Vidal, C. (1999): "Objectives, tools and nomenclatures. In Eurostat: Land Cover and Land Use information systems for European Union Policy needs", in: Proceedings of the seminar 1998, Luxembourg 21 - 23 January, EC.

Egaña, P. P. C. \& Palma, C. (1999): Catastro y Evaluación de Recursos Vegetacionales Nativos de Chile. Protocolo de Acuerdo CONAF-CONAMA. Santiago de Chile, Universidad Austral de Chile/Pontificia Universidad Católica de Chile/Universidad Católica de Temuco.

Eiten, G. (1968): "Vegetation forms. A classification of stands of vegetation based on structure, growth form of the components, and vegetative periodicity". Boletim do Instituto de Botanica, 4.

European, C. (1993): CORINE Land Cover guide technique. Luxembourg, European Enviroment Agency, OPOCE, 130 pp.

FAO. Departamento de Pesca, Organización de las Naciones Unidas para la Agricultura y la Alimentación, (2009): El estado mundial de la pesca y la acuicultura 2008. Roma, Food \& Agriculture Org.. http://www.fao.org/docrep/011/i0250s/i0250s00.htm (Verificada el 1/5/2015) 
Fosberg, F. R. (1961): "A classification of vegetation for general purposes". Tropical Ecology, 2, pp. 1-28.

Franklin, J.; Phinn, S. R.; Woodcock, C. E. \& Rogan, J. (2003): "Rationale and conceptual framework for classification approaches to assess forest resources and properties", in M. Wulder \& S. E. Franklin, (eds): Methods and Applications for Remote Sensing of Forests: Concepts and Case Studies. Dordrecht, Kluwer Academic Publishers, pp. 279-300.

Fundación CEQUA, (2007): Actualización de las bases para una estrategia para la conservación de mamíferos marinos en la región de Magallanes y Antártica chilena. Informe final. Punta Arenas, $151 \mathrm{pp}$.

Gallegos, A. \& Donoso, J. (1997): "Energía y seguridad nacional". FASOC, 12/1, pp. 42-47.

Haberl, H.; Wackernagel, M.; Krausmann, F; Erb, K.-H. \& Monfreda, C. (2004): "Ecological footprints and human appropriation of net primary production: a comparison". Land Use Policy, 21/3, pp. 279-288.

Inostroza, L. (2008): "Turismo en la Patagonia: una Amenaza para la Integridad Ecológica del Medio Natural”. CIUR, 56, pp. 122.

Inostroza, L. (2012): "Patagonia, Antropización de un Territorio Natural". CIUR, 83, pp. 86.

Kuechler, A. W. \& Zonneveld, I. S. (eds.) (1988): Vegetation Mapping. Handbook of Vegetation Science, vol. 10. Dordecht, the Netherlands, Kluwer Academic.

Loveland, T. R.; Sohl, T. L.; Stehman, S. V.; Gallant, A. L.; Sayler, K. L. \& Napton, D. E. (2002): "A Strategy for estimating the rates of recent United States land-cover changes". Photogrammetric Engineering \& remote Sen, 68/10, pp. 1091-1099.

Lunetta, R. S. \& Elvidge, C. D. (1998): Remote Sensing Change Detection: Environmental Monitoring Methods and Applications. Chelsea, Ann Arbor Press, 318 pp.

Martinic, M. (2004): "La minería del carbón en magallanes entre 1868-2003". Historia, I/37, pp. 129-167.

Meinel, G. \& Hennersdorf, J. (2002): "Classifications systems of land cover and land use and their challenges for picture processing of Remote Sensing data-Status of international discussion and programs", in: Proc. 3rd Int. Symp. Remote Sens. of urban areas, Istambul, pp. 472-479. http://citeseerx.ist.psu.edu/viewdoc/download? doi=10.1.1.198.3112\&rep=repl\&type=pdf (Verificada el 1/5/2015).

Mueller-Dombois, D. \& Ellenberg, J. H. (1974): Aims and Methods of Vegetation Ecolo gy. New York, John Wiley and soons.

Murray, I.; Blázquez, M. \& Rullan, O. (2005): "Los cambios en la cobertura de la Tierra. Una revisión bibliográfica desde la Geografía". Revista Bibliográfica de Geografía y Ciencias Sociales, X/571, pp. 1-16.

Pillet, F. (2003): "El espacio geográfico y el estudio del espacio humanizado en la sociedad global". Estudios Geográficos, LXIV/250, pp. 47-62.

RAE, Real Academia Española de la Lengua, (2001): Diccionario de la Lengua Española. Madrid, Espasa Calpe, XXII Edición. 
Rogan, J. \& Chen, D. (2004): "Remote sensing technology for mapping and monitoring land-cover and land-use change". Progress in Planning, 61/4, pp. 301-325.

Romero-Calcerrada, R.; Perry, G. L. \& Viegas, D. X. (2002): "Landscape change pattern (1984-1999) and implications for fire incidence in the SPA Encinares del rio Alberche y Cofio (Central Spain)", in: Forest fire research and wildland fire safety: Proceedings of IV International Conference on Forest Fire Research 2002 Wildland Fire Safety Summit, Luso, Coimbra, Portugal. November 2002. Millpress Science Publishers. pp. 18-23.

Valera Lozano, A.; Añó Vidal, C. \& Sánchez Díaz, J. (2012): "Cambios en los usos y coberturas del suelo en el municipio de Elx (1956-2005)". Estudios Geográficos, 72/271, pp. 681-703.

UNESCO (1973): International Classification and Mapping of Vegetation. Paris.

Wrbka, T.; Erb, K.-H.; Schulz, N. B.; Peterseil, J.; Hahn, C. \& Haberl, H. (2004): "Linking pattern and process in cultural landscapes. An empirical study based on spatially explicit indicators". Land Use Policy, 21/3, pp. 289-306.

\section{SITIOS WEB}

CATAMUTUN, Industria nacional del carbón, consultado el 21.09.2009. http://www. catamutun.com/produc/carbon/pais.html (Verificada el 1/5/2015).

ENAP Empresa Nacional del Petróleo, 2000 Memoria Anual 2000, Santiago de Chile. http://www.google.cz/url? sa=t\&rct=j\&q=\&esrc=s\&source=web\&cd=3\&ved=0CDA QFjAC\&url=http\%3A\%2F\%2Fwww.enap.cl\%2Fdescarga\%2Fforzada\%2F747\&ei=B iZHVci7NMrOUIfLgPgP\&usg=AFQjCNEViL-kJbZbh9QC46dCacZq82En9g\&sig2 =x0XaEgtJ6xbyeOcQ6S3t_Q\&bvm=bv.92291466,d.d24 (Verificada el 1/5/2015).

SERNAGEOMIN, Sitio de concesiones en línea, consultas hechas desde el 07 de febrero hasta el 15 de marzo de 2010, http://catastro.sernageomin.cl/. (Verificada el $1 / 5 / 2015)$

Mapa Geológico de Chile: versión digital. Servicio Nacional de Geología y Minería, Publicación Geológica Digital, No. 4 (CD-ROM, versión 1.0, 2003). Santiago. http://www.ipgp.fr/ dechabal/Geol-millon.pdf. (Verificada el 1/5/2015).

SERNATUR Servicio Nacional de Turismo, (2006): Plan de Acción de Turismo 2006-2010. http://www.parquenahuelbuta.cl/central/documentos/4bdb2d7025973ca9b6edeea 7fe489b7d.pdf. (Verificada el 1/5/2015).

Servicio Nacional de Turismo, Departamento de Planificación, (2009): Zonas y centros de interés turístico nacional. Antecedentes básicos para una estrategia de ordenamiento territorial. Santiago de Chile, sin publicar, 19 pp. http://www.google.cz/url?sa= $\mathrm{t} \& \mathrm{rct}=\mathrm{j} \& \mathrm{q}=\& \mathrm{esrc}=\mathrm{s} \&$ source=web $\& \mathrm{~cd}=1 \& \mathrm{ved}=0 C C E Q F j A A \& u r l=\mathrm{http} \% 3 \mathrm{~A} \% 2 \mathrm{~F} \%$ 2Fwww.sernatur.cl\%2Fwp-content\%2Fplugins\%2Fdownload-monitor\%2Fdown load.php\%3Fid\%3DZOITYC1.pdf\&ei=WyhHVdecO4f3UquUgAg\&usg=AFQjC 
NEDDnV4vmLjinhK1dvrUrudHSFmvQ\&sig2=m2jdwZGsnR4eU3qROU1FNw\& bvm=bv.92291466,d.d24. (Verificada el 1/5/2015).

SERNAPESCA, Estadísticas de pesca artesanal y acuicultura. Consultado el 08.07.2010. http://www.sernapesca.cl/index.php?option=com_remository\&Itemid $=54 \&$ func= select\&id=2. (Verificada el 1/5/2015). http://www.sernapesca.cl/index.php?option $=$ com_remository\&Itemid=54\&func=fileinfo\&id=3434. (Verificada el 1/5/2015). http://www.sernapesca.cl/index.php?option=com_remository\&Itemid=54\&func=fileinfo\&id=4287. (Verificada el 1/5/2015).

\section{RESUMEN}

Los métodos de clasificación de usos del suelo en regiones remotas presentan dos serias limitaciones. La primera es la mixtura conceptual de usos con coberturas que no refleja el uso efectivo del territorio. Una segunda limitación es la ausencia de usos importantes como turismo, acuicultura y minería, que imponen importantes presiones sobre territorios frágiles. Este trabajo presenta un método para determinar los usos territoriales en la región de Magallanes en el extremo austral de Chile. Se trata de una clasificación de usos del suelo elaborada específicamente para este territorio, conceptualmente clara y amplia, que permite establecer el alcance efectivo de las explotaciones territoriales, determinando qué territorios son utilizados y cuales permanecen sin uso. El método está basado íntegramente en un SIG y constituye un insumo clave para mejorar la gestión territorial. El análisis refleja un alto porcentaje de uso directo, contrario a la percepción de pristinidad existente, lo que genera importantes desafíos para las actuales estrategias de gestión territorial.

PAlabras Clave: Patagonia; pristinidad; usos/covertura del suelo; uso forestal, minería y acuicultura; SIG.

\section{ABSTRACT}

The current classification methods of land use in remote regions have two serious limitations. The first is the conceptual mixture between land uses and covers, which does not reflect the actual direct use of land. A second limitation is the absence of important uses such as tourism, aquaculture and mining, which impose significant pressures on fragile territories. This paper presents a land use classification method developed specifically for the region of Magellan in the extreme south of Chile. It is a land use classification wide and conceptually clear, which allows an effective determination of the range of land exploitations in Patagonia, determining which areas are used and which remain unused. The method is based entirely on a GIS and is a key input for improving land management. The analysis shows a high percentage of direct use, contrary to the existing pristine perception, which imposes significant challenges for current land management strategies.

KEY WORDS: Patagonia pristine; land use/cover; forest use, mining, aquaculuture, GIS. 


\section{RÉSUMÉ}

Les méthodes de classification de l'utilisation du sol dans les régions reculées présentent deux limitations graves. La première est le mélange conceptuel d'utilisations avec une couverture qui ne reflète pas l'utilisation réelle de la terre. Une seconde limite est l'absence d'usages importants tels que le tourisme, l'aquaculture et l'exploitation minière, qui imposent de fortes pressions sur les terres fragiles. Cet article présente une méthode pour déterminer l'utilisation des terres dans la région de Magallanes à l'extrême sud du Chili. Il s'agit d'une classification de l'utilisation des sols développée spécifiquement pour ce territoire, conceptuellement claire et large, qui permet de déterminer la portée effective des exploitations territoriales, identifier les zones utilisées et celles qui restent inutilisées. La méthode est basée entièrement sur un SIG et est un élément clé pour améliorer la gestion des terres. Lanalyse montre un pourcentage élevé d'utilisation directe, contrairement à la perception de nature intacte existante, créant des défis importants pour les stratégies actuelles de gestion des terres.

MoTS CLÉs: Patagonia; terre vierge; utilisation du sol/couverture; foresterie; des mines et de l'aquaculture; SIG. 